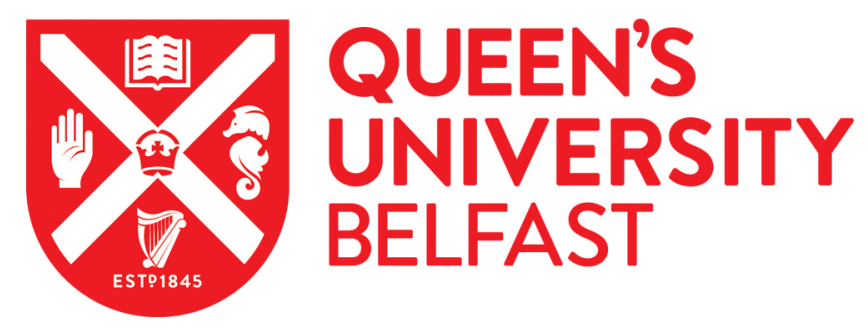

\title{
Detection of tetrodotoxins in juvenile pufferfish Lagocephalus sceleratus (Gmelin, 1789) from the North Aegean Sea (Greece) by an electrochemical magnetic bead-based immunosensing tool
}

Leonardo, S., Kiparissis, S., Rambla-Alegre, M., Almarza, S., Roque, A., Andree, K. B., Christidis, A., Flores, C., Caixach, J., Campbell, K., Elliott, C. T., Aligizaki, K., Diogène, J., \& Campàs, M. (2019). Detection of tetrodotoxins in juvenile pufferfish Lagocephalus sceleratus (Gmelin, 1789) from the North Aegean Sea (Greece) by an electrochemical magnetic bead-based immunosensing tool. Food Chemistry, 290, 255 - 262. https://doi.org/10.1016/j.foodchem.2019.03.148

Published in:

Food Chemistry

Document Version:

Peer reviewed version

Queen's University Belfast - Research Portal:

Link to publication record in Queen's University Belfast Research Portal

\footnotetext{
Publisher rights

Copyright 2019 Elsevier. This manuscript is distributed under a Creative Commons Attribution-NonCommercial-NoDerivs License (https://creativecommons.org/licenses/by-nc-nd/4.0/), which permits distribution and reproduction for non-commercial purposes, provided the author and source are cited.
}

\section{General rights}

Copyright for the publications made accessible via the Queen's University Belfast Research Portal is retained by the author(s) and / or other copyright owners and it is a condition of accessing these publications that users recognise and abide by the legal requirements associated with these rights.

\section{Take down policy}

The Research Portal is Queen's institutional repository that provides access to Queen's research output. Every effort has been made to ensure that content in the Research Portal does not infringe any person's rights, or applicable UK laws. If you discover content in the Research Portal that you believe breaches copyright or violates any law, please contact openaccess@qub.ac.uk. 
Detection of tetrodotoxins in juvenile pufferfish Lagocephalus sceleratus (Gmelin, 1789) from the North Aegean Sea (Greece) by an electrochemical magnetic bead-based immunosensing tool

Sandra Leonardoa, Sotiris Kiparissis ${ }^{b}$, Maria Rambla-Alegrea, Sergi Almarzaa, Ana Roquea, Karl B. Andree $^{a}$, Aris Christidis ${ }^{b}$, Cintia Flores ${ }^{c}$, Josep Caixach ${ }^{c}$, Katrina Campbelld , Christopher T. Elliott ${ }^{d}$, Katerina Aligizakie, Jorge Diogène ${ }^{a}$, Mònica Campàsa

aIRTA, Ctra. Poble Nou, km 5.5, 43540 Sant Carles de la Ràpita (Tarragona), Spain

${ }^{b}$ Hellenic Agricultural Organization-DEMETER, Fisheries Research Institute, 64007, Nea Peramos, Kavala, Greece

'Mass Spectrometry Laboratory/Organic Pollutants, IDAEA-CSIC, Jordi Girona 18, 08034 Barcelona, Spain

IInstitute for Global Food Security, School of Biological Sciences, Queen's University Belfast, David Keir Building, Stranmillis Road, Belfast, Northern Ireland, UK, BT9 5AG

eLaboratory Unit on Harmful Marine Microalgae, School of Biology, Aristotle University of Thessaloniki, Greece

*e-mail: monica.campas@irta.cat

\section{Abstract}

Two small Lagocephalus sceleratus juveniles were captured in picarel targeting catches from North Aegean Sea (Greece) in the autumn of 2017. An electrochemical immunosensing tool using magnetic beads as immobilisation support was developed and applied to the rapid 
screening of tetrodotoxins (TTXs), potent neurotoxins that constitute a food safety hazard when present in seafood. This tool revealed the presence of TTXs in both individuals. Results were compared with those provided by mELISA and LC-HRMS, the latter confirming the presence of TTX. Some of the tissues contained TTX contents close to or above $2 \mathrm{mg} / \mathrm{kg}$. L. sceleratus juveniles had been considered as non-toxic and, to our knowledge, this is the first report of high TTX levels in small L. sceleratus individuals. Such specimens can be mistaken with other edible species, posing a threat to consumers. The availability of low-cost and user-friendly tools for TTXs detection will contribute to guarantee seafood safety.

\section{INTRODUCTION}

The Suez Canal is considered as the major route for migration of indo-pacific marine species from the Red Sea into the Mediterranean, which is also referred to as Lessepsian migration. Following the salinity increase of the Nile estuary (after the construction of the Aswan dam) and the increase of the water temperatures in the last twenty years, the Eastern Mediterranean Sea is gradually becoming a more suitable environment for the establishment, growth and reproduction of alien species from warmer waters, which can compete with the native ones. Today, more than 443 aquatic species from various taxonomic groups have entered the Eastern Mediterranean through the Suez Canal (Galil et al., 2015). Among the most devastating Lessepsian migrant species are the highly toxic silver-cheeked toadfish (Lagocephalus sceleratus (Gmelin, 1789)) (Nader, Indary \& Boustany, 2012). Its presence in the Mediterranean was reported for the first time in Gökova Bay, Turkey, in 2003 (Akyol, Ünal, Ceyhan \& Bilecenoglu, 2005). Since then, its occurrence in several locations of the Mediterranean has dramatically increased, revealing a rapid spread towards the West of the Mediterranean, reaching Greece in 2005 (Kasapidis, Peristeraki, Tserpes \& Magoulas, 2007), Algeria in 2013 (Kara, Ben Lamine \& Fancour, 2015), and Spain in 2014 (Katsanevakis et al., 2014). It is one of the fastest expanding 
Lessepsian fishes (Peristeraki, Lazarakis, Skarvelis, Georgiadis \& Tserpes, 2006). Nowadays, in the SE Mediterranean areas $L$. sceleratus is very abundant and constitutes a true nuisance to the fishermen, damaging the nets and the longlines or even spoiling the catch by attacking the captured fish (Kalogirou, 2013).

However, an even greater concern regarding this species has been raised because of its high toxicity due to tetrodotoxin (TTX) that it contains in its body tissues. Tetrodotoxin is one of the most potent natural neurotoxins, responsible for many human intoxications and fatalities, usually following the consumption of pufferfish (Bane, Lehane, Dikshit, O'Riordan \& Furey, 2014). Tetrodotoxin is produced by certain marine endosymbiotic bacteria and enters into other organisms through the food webs (Margarlamov, Melnikova \& Chernyshev, 2017). Although, according to the legislation of many Mediterranean countries (e.g. EC, 2004a; 2004b) Tetraodontidae species and their products should not be marketed, cases of TTX poisoning due to the ingestion of L. sceleratus have been reported in the Mediterranean (Bentur et al., 2008; Chamandi, Kallab, Mattar \& Nader, 2009; Kheifets, Rozhavsky, Solomonovich, Marianna \& Soroksky, 2012). The consumption of this fish was probably due to the unawareness of the danger of this species. A second important reason for concern is the possible mixing of the L. sceleratus juveniles with other commercial small fish (Kiriake, Ohta, Okayama, Matsuura, Ishizaki \& Nagashima, 2016). In the Mediterranean, there are several unofficial reports from North Aegean and Crete (Christidis, Peristeraki, personal observations) of small L. sceleratus juveniles intermingled with other small pelagic species (anchovy, sardines, picarel and bogue), primarily in catches coming from beach seines and incidentally in catches from purse seines (Christidis, personal observations). This fact may result in their accidental consumption in case they are not detected by the fishermen and reach the market. Regarding the toxicity of L. sceleratus, it generally depends on the maturity stage of the fish (Sabrah, El-Ganainy \& Zaky, 2006; Nader et al., 2012), juveniles being considered as non-toxic (Sabrah et al., 2006; Katikou, Georgantelis, Sinouris, Petsi \& Fotaras, 2009; Rodríguez, Alfonso, Otero, Katikou, Georgantelis 
\& Botana, 2012). Since data about the toxicity are scarce, we hypothesise that $L$. sceleratus juveniles may be toxic even at very young stages in certain occasions, a situation that can possibly pose a serious health hazard. Knowledge of the TTX contents in L. sceleratus during the early life stages requires careful attention in order to evaluate the overall risk that this species may represent for consumers.

Different methodologies have been developed for the detection of TTXs, being the mouse bioassay (MBA) (Sabrah et al., 2006; Katikou et al., 2009) and liquid chromatography coupled to mass spectrometry analysis (Rambla-Alegre et al., 2017) the most widely used. The MBA provides an overall estimation of the total toxicity of the sample, but it is a non-specific method and cannot clearly discriminate between TTXs and saxitoxins (STXs). Instrumental analysis methods allow the identification and quantification of individual toxin analogues according to their structure and physicochemical properties. Recently, mass spectrometry has been combined with a nanofiber-based solid phase microextraction for in vivo sampling and detection of TTX in pufferfish (Tang, Huang, Xu, Ouyang \& Liu, 2018).

Immunoassays and immunosensors are attractive candidates for the rapid screening of TTXs due to their high specificity and sensitivity as well as their low cost, ease of use and rapidity. To date, most immunochemical tools for the detection of TTXs are colorimetric immunoassays (Reverté, Soliño, Carnicer, Diogène \& Campàs, 2014; Reverté et al., 2015, 2018; Rambla-Alegre et al., 2018), although several optical immunosensors (Leonardo, Reverté, Diogène \& Campàs, 2016; Reverté et al., 2017a) and a few electrochemical immunosensors (Kreuzer, Pravda, O'Sullivan \& Guilbault, 2002; Neagu, Micheli \& Palleschi, 2006; Reverté, Campbell, Rambla-Alegre, Elliott, Diogène \& Campàs, 2017b) have also been developed. Biosensors provide more compact and automated tools than conventional immunoassays and, amongst them, electrochemical biosensors stand out because of their inherent high sensitivities, the low cost and possibility for miniaturization of electrodes and potentiostats, as well as their high versatility, reliability and 
short analysis times (Leonardo, Toldrà \& Campàs, 2017). When developing electrochemical immunosensors, the immobilisation of the recognition element on the electrode surface plays an important role, not only in the antibody/antigen interaction but also in the modification of the sensing surface properties. Coating of the electrode surface with immunoreagents or nonspecific adsorption of other compounds present in the sample may hinder the electron transfer. These limitations can be overcome by the use of magnetic beads (MBs) as alternative immobilisation supports, which provide advantages such as a higher surface area available for biomolecule immobilisation, improved assay kinetics, more efficient washing steps or lower matrix effects (Pividori \& Alegret, 2010; Pinacho, Sánchez-Baeza, Pividori \& Marco, 2014). Moreover, by only placing a magnet below the working electrode, the MB-immunocomplex is immobilised on the electrode surface and the enzyme substrate development takes place close to the transducer, thus not compromising the sensitivity of the method.

In this work, we report the development of an electrochemical MB-based immunosensing tool for the detection of TTXs. TTX has been conjugated to maleimide-activated MBs through the formation of cysteamine self-assembled monolayers (SAMs), thus providing an oriented and stable TTX immobilisation. After optimisation of the experimental parameters by colorimetry, TTX-MB immunocomplexes have been combined with electrode arrays as transducer elements and amperometry as the electrochemical detection method. This rapid and reliable immunosensing tool has been applied to the analysis of two juvenile pufferfish L. sceleratus individuals caught in the North Aegean Sea in October 2017. Results have been compared with those achieved by liquid chromatography coupled to high resolution mass spectrometry (LCHRMS) analysis, and the maleimide-based ELISA (mELISA) previously developed at IRTA for the detection of TTXs in shellfish (Reverté et al., 2018) and in urine samples (Rambla-Alegre et al., 123 2018). By combining the immunochemical tools and instrumental methods, the presence of significant TTX contents in pufferfish at very early stages has been confirmed for the first time. 


\section{MATERIAL AND METHODS}

\subsection{Reagents and solutions}

TTX standard was purchased from Tocris Bioscience (Bristol, UK) and the standard solution was prepared at $1 \mathrm{mg} / \mathrm{mL}$ in $3 \mathrm{mM}$ sodium acetate, $\mathrm{pH} 4.8$. The anti-TTX monoclonal antibody TX-7F (mAb) was produced as described in Kawatsu, Hamano, Yoda, Terano \& Shibata (1997). PureCube maleimide-activated MagBeads (MBs) were obtained from Cube Biotech (Monheim, Germany). Pierce maleimide-activated plates were achieved from Thermo Fisher Scientific (Madrid, Spain). Cysteamine hydrochloride, formaldehyde solution, anti-mouse IgG (whole molecule)-horseradish peroxidase antibody produced in rabbit (IgG-HRP), bovine serum albumin (BSA), sodium acetate, potassium phosphate dibasic, potassium phosphate monobasic, ethylenediaminetetraacetic acid (EDTA), Tween-20 and 3,3',5,5'-tetramethylbenzidine (TMB) liquid substrate were supplied by Sigma-Aldrich (Tres Cantos, Spain). HPLC-grade acetonitrile $(A C N)$, glacial acetic acid $(A A)$ and methanol $(\mathrm{MeOH})$ were obtained from Chem-lab (Zedelgem, Belgium). Ultrapure Milli-Q water $(18.2 \mathrm{M} \Omega / \mathrm{cm})$ was used for the preparation of solutions 140 (Millipore Iberica Ltd., Madrid, Spain).

\subsection{Equipment, electrodes and software}

Magnetic separation was performed using a MagneSphere Technology Magnetic Separation Stand (for 12 0.5-mL tubes) and a PolyATract System 1000 Magnetic Separation Stand (for one 15-mL tube) from Promega Corporation (Madison, WI, USA). Instruments, Inc. (Winooski, VT, USA). Gen5 software was used to collect and evaluate data. 

provided by Dropsens S.L. (Oviedo, Spain). Arrays consisted of 8 carbon working electrodes of $2.5 \mathrm{~mm}$ in diameter, each with its own carbon counter electrode and silver reference electrode. Amperometric measurements were performed with a PalmSens potentiostat connected to an 8-channel multiplexer (MUX8) (Houte, The Netherlands). Data were collected and evaluated with PalmSens PC software.

LC-HRMS analysis was carried out with an Orbitrap-Exactive HCD and data was processed with Xcalibur 3.1. software (Thermo Fisher Scientific, Bremen, Germany).

\subsection{Pufferfish sampling and processing}

Two juvenile fish of 53 and $59 \mathrm{~mm}$, morphologically identified as L. sceleratus, were captured in

Chrousou Bay (Chalkidiki, Greece, North Aegean Sea) in October 2017 (Figure 1). The fish were intermingled in the catch consisting mainly of Spicara smaris of a beach seine in depths ranging from 10 to $30 \mathrm{~m}$ depth. The specimens were brought to the laboratory and frozen at $-20^{\circ} \mathrm{C}$ until analysis.

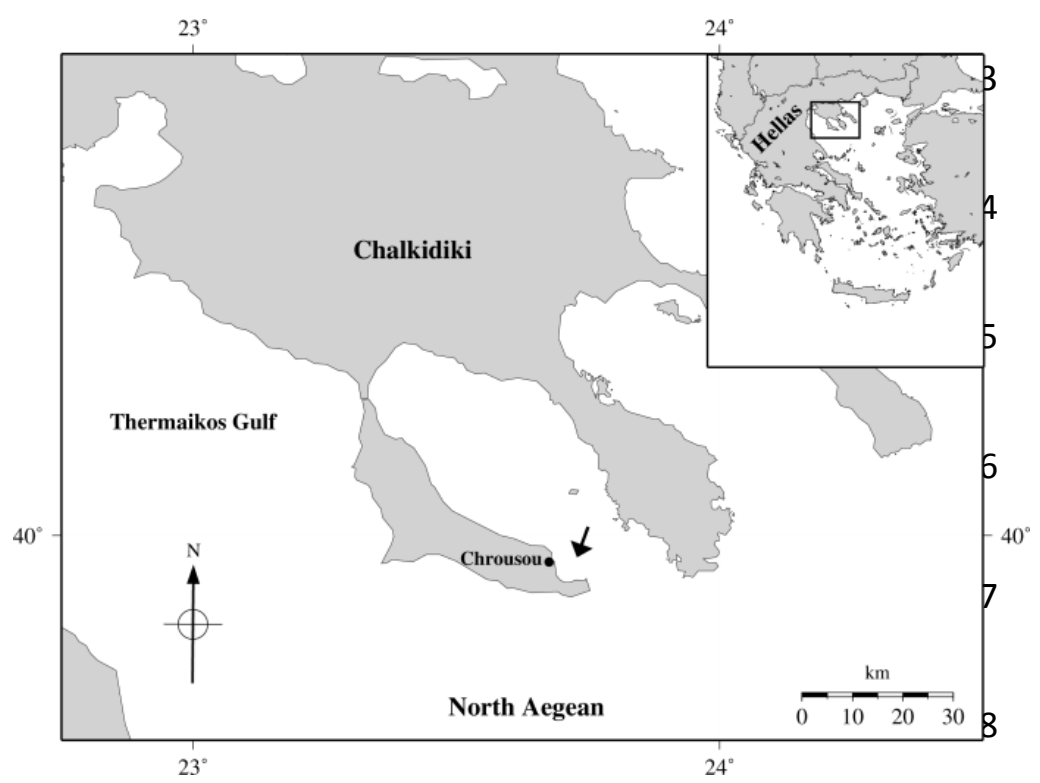

Figure 1. Sampling area of the two juvenile pufferfish Lagocephalus sceleratus of this study. 
Both pufferfish were dissected into different tissues. For toxin analysis, muscle (M\#1) and skin

172 (S\#1) from pufferfish 1, and muscle (M\#2), skin (S\#2) and internal organs(O\#2) containing liver and intestinal tract from pufferfish 2 were homogenised using a glass stirring rod. For microbiological analysis, homogenates from muscle (M), skin (S), liver (L) and intestinal tract (IT) tissues from both pufferfish were used. Gonads were not present because of the lack of maturity of both individuals. The remaining skeletal parts were kept at $-20{ }^{\circ} \mathrm{C}$ for DNA extraction and sequence analysis.

\subsection{Pufferfish DNA extraction and sequencing}

DNA was extracted from $50 \mathrm{mg}$ of the remaining bone tissue of each L. sceleratus specimen using a DNeasy Blood and Tissue Kit (Qiagen, Barcelona, Spain) following the manufacturer's protocol. Extracted DNA was analysed by spectrophotometry (GeneQuant, Amersham Biosciences) to measure the concentration and check purity. DNA samples were diluted to $50 \mathrm{ng} / \mu \mathrm{L}$ and one microliter subjected to PCR amplification of the mitochondrial cytochrome oxidase gene using previously described primers (Kochzius et al., 2010). The resulting amplicon was purified (QIAquick PCR Purification Kit, Qiagen, Barcelona, Spain) and sequenced (Sistemas Genómicos, Valencia, Spain). A BLAST analysis was performed to compare similarity of sequences obtained to known sequences from the GenBank database (NCBI).

\subsection{Bacterial culture and DNA sequencing}

Homogenates of muscle (M), skin (S), liver (L) and intestinal tract (IT) tissues from the two juvenile pufferfish were inoculated on thisosulphate citrate bile sucrose (TCBS) agar (Sharlab, 
194 (Sharlab, Sentmenat, Spain) for isolation of general heterotroph bacteria. Plates were incubated 195 at $30{ }^{\circ} \mathrm{C}$ for $48 \mathrm{~h}$. The dominant colony morphotype from each plate was isolated and purified. Genomic DNA of each purified isolate was extracted using the Wizard Genomic DNA Purification Kit (Promega, Alcobendas, Spain), following the manufacturer's protocol. The 16S rRNA was PCR amplified using the forward and reverse primers $27 \mathrm{~F}$ and $1492 \mathrm{R}$ (Lane, 1991). PCR products were purified using the QIAquick PCR Purification Kit (Qiagen, Barcelona, Spain) and sequenced (Sistemas Genómicos, Valencia, Spain). Consensus sequences were compared to those available in GenBank (NCBI) using the BLAST algorithm.

202

\subsection{Tetrodotoxins (TTXs) extraction}

A double TTX extraction was performed with $0.1 \%$ acetic acid as previously described (Reverté et al., 2015), adjusting the protocol to the small amounts of tissue. Thus, muscle (M\#1) and skin (S\#1) extracts from pufferfish 1 were obtained at a tissue concentration of 117 and $86 \mathrm{mg}$ equiv./mL, respectively. Muscle (M\#2), skin (S\#2) and internal organs (O\#2) from pufferfish 2 were obtained at tissue concentrations of 122,58 and $15 \mathrm{mg}$ equiv. $/ \mathrm{mL}$. The analysis by the electrochemical MB-based immunosensing tool and mELISA was performed directly with the aqueous extracts. For the LC-HRMS analyses, extracts were evaporated, re-dissolved in $\mathrm{MeOH}$ and filtered through $0.2-\mu \mathrm{m}$ polytetrafluoroethylene (PTFE) filters.

\subsection{Immunosensing approach}

214 First, the TTX-MB conjugate was prepared as follows: (1) $6.25 \mu \mathrm{L}$ of maleimide-activated MBs 215 were transferred to a tube and rinsed with washing buffer (0.1 M PBS, 0.05\% Tween $^{\circledR}-20$, pH 2167.2 ) and vigorous mixing; for the washing steps, the tube was placed on the magnetic separation stand and the washing solution was removed; (2) $500 \mu \mathrm{L}$ of $1 \mathrm{mM}$ cysteamine in binding buffer 
218 (0.1 M PBS, 10 mM EDTA, pH 7.2) was added and incubated for $2 \mathrm{~h}$ at room temperature; (3)

219 after three washing steps, $500 \mu \mathrm{L}$ of $\mathrm{TTX}$ solution $(25 \mu \mathrm{g} / \mathrm{mL})$ in binding buffer containing $10 \%$

220 formaldehyde was added and incubated overnight at $4{ }^{\circ} \mathrm{C}$; (4) three washing steps were

221 performed and the TTX-coated MBs were resuspended in $500 \mu \mathrm{L}$ of binding buffer. When amounts of MB varied, volumes were adjusted proportionally.

Once the TTX-MB conjugate was ready, (5) $50 \mu \mathrm{L}$ of the conjugate was transferred to a new tube, the supernatant was removed and $25 \mu \mathrm{L}$ of binding buffer for the optimisation or TTX standard solution for the competition and $25 \mu \mathrm{L}$ of anti-TTX mAb dilution (from $1 / 500$ to $1 / 4000$ for the optimisation and 1/2000 for the competition) in 1\% BSA-binding buffer were added and incubated for 30 min at room temperature; (6) after three washing steps, a blocking step was performed with $100 \mu \mathrm{L}$ 1\% BSA-binding buffer for $30 \mathrm{~min}$; (7) after three washing steps, $50 \mu \mathrm{L}$ of 1/1000 IgG-HRP dilution in 1\% BSA-binding buffer was incubated for 30 min; (8) three washing steps were performed and the immunocomplex was resuspended in $50 \mu \mathrm{L}$ and $2.5 \mu \mathrm{L}$ of binding buffer for the colorimetric optimisation and the electrochemical immunosensing tool, respectively.

For the colorimetric optimisation of the protocol: (9) $40 \mu \mathrm{L}$ of immunocomplex was transferred to a new tube and after supernatant removal, $125 \mu \mathrm{L}$ of TMB liquid substrate was added and incubated for $10 \mathrm{~min}$; (10) the tube was placed on the magnetic separation stand and $100 \mu \mathrm{L}$ of TMB liquid substrate was collected for the colorimetric measurement at $620 \mathrm{~nm}$ in a microtiter plate. For the electrochemical immunosensing tool: (9) $2.5 \mu \mathrm{L}$ of immunocomplex was placed on each working electrode of the 8-electrode array with a magnetic support on the back, the magnetic immunocomplex was trapped, and the supernatant was removed; (10) $10 \mu \mathrm{L}$ of TMB liquid substrate was incubated for 2 min; (11) TMB oxidation was measured by amperometry, applying $-0.2 \mathrm{~V}$ (vs. Ag) for $10 \mathrm{~s}$, and recording the reduction current. 


\subsection{LC-HRMS analysis}

245 The quantification of TTXs contents in the juvenile pufferfish extracts was performed following the protocol reported in Rambla-Alegre et al. (2017). Briefly, analytical separation was performed on a HILIC XBridge Amide column; a binary gradient elution was programmed with water (mobile phase A) and acetonitrile/water (mobile phase B), both containing ammonium acetate. ESI parameters and voltages were optimised to: spray voltage of $3.5 \mathrm{kV}$, capillary temperature of $300{ }^{\circ} \mathrm{C}$, sheath gas flow rate of 40 (arbitrary units) and auxiliary gas flow rate of 10 (arbitrary units), capillary voltage of $30.0 \mathrm{~V}$, tube lens voltage of $130 \mathrm{~V}$ and skimmer voltage of $28 \mathrm{~V}$ were used. The working mass range was $\mathrm{m} / \mathrm{z} 100-1200$ in full scan acquisition mode. The resolution was 50000 ( $\mathrm{m} / \mathrm{z}$ 200, FWHM) at a scan rate of $2 \mathrm{~Hz}$. The automatic gain control (AGC) was set as "balanced (1e6)" with a maximum injection time of 250 ms. Peaks were identified by retention time, exact mass (mass window $\pm 5 \mathrm{ppm}$ ) and isotope pattern ratio.

\section{9. $\mathrm{mELISA}$}

Pufferfish samples were analysed by mELISA using the protocol previously developed by our group for the determination of TTXs in shellfish (Reverté et al., 2018) and in urine (RamblaAlegre et al., 2018). Briefly, $100 \mu \mathrm{L}$ of $1 \mathrm{mM}$ cysteamine in binding buffer (0.1 M potassium phosphate, 10 mM EDTA, pH 7.2) was added to maleimide-activated plates and incubated for $3 \mathrm{~h}$, followed by the direct immobilisation of TTX $(2 \mu \mathrm{g} / \mathrm{mL})$ with formaldehyde (3.4\%) in the same buffer overnight at $4{ }^{\circ} \mathrm{C}$. A competitive assay was then performed by incubating $50 \mu \mathrm{L}$ of free TTX/sample dilution and $50 \mu \mathrm{L}$ of 1/1600 anti-TTX mAb dilution in 1\% BSA-binding buffer for 30 min. Afterwards, a blocking step was performed with $200 \mu \mathrm{L}$ of 1\% BSA-binding buffer for 30 min and, finally, $100 \mu \mathrm{L}$ of IgG-HRP at 1/1000 dilution in 1\% BSA-binding buffer was incubated 
267 for $30 \mathrm{~min}$. The colorimetric response was measured at $620 \mathrm{~nm}$ after $10 \mathrm{~min}$ of TMB liquid 268 substrate incubation.

\subsection{Data analysis}

271 Measurements were performed in triplicate for the colorimetric optimisation of the protocol,

272 the electrochemical MB-based immunosensing tool and MELISA, and in duplicate for LC-HRMS analysis. Immunosensing calibration curves were fitted using a sigmoidal logistic four-parameter equation. To evaluate differences between approaches, data were first tested for normality. To compare values from two different groups, the t-test was used for normally distributed data sets. Differences were considered statistically significant at the 0.05 level. SigmaStat 3.1. was used for statistical analysis.

\section{RESULTS}

\subsection{Pufferfish identification}

The two juvenile fish captured in the North Aegean Sea in October 2017 were 5-6 cm in length and weighed $\sim 2 \mathrm{~g}$ each. Both individuals were dark grey-brownish with black spots of equal size regularly distributed in the dorsal part, a wide silver band present on the lower parts of the flanks, a silver blotch in the front of the eyes, and with the pectoral fin base black and the belly white. Their meristics were in accordance with those provided by Smith and Heemstra (1986) and Golani and Levy (2005) for L. sceleratus. DNA extraction and PCR amplification provided PCR products of approximately $800 \mathrm{bp}$ long for both individuals. The BLAST analysis showed that the sequence obtained was $100 \%$ similar to L. sceleratus, supporting the morphological identification. 


\subsection{Optimisation of the MB-based immunosensing approach by colorimetry}

292

293

294

295

296

297

298

299

300

Maleimide-activated MBs were used for the self-assembling of cysteamine and the subsequent covalent binding of TTX, shifting the competitive immunoassay for TTXs detection from the microtiter plate configuration previously reported by our group (Reverté et al., 2018) to the use of MBs as immobilisation supports. First, TTX concentrations from 0.3 to $10 \mu \mathrm{g} / \mathrm{mL}$ were tested for the toxin conjugation to $2 \mu \mathrm{L}$ of MBs. Absorbance values increased with TTX concentration and no saturation was observed. Consequently, to achieve a complete TTX coating of the MBs and thus reduce non-specific adsorption and optimise the amount of MBs per assay, higher TTX concentrations (from 12.5 to $50 \mu \mathrm{g} / \mathrm{mL}$ ) and lower MB volumes (0.5 $\mu \mathrm{L}$ ) were used. Under these conditions, a TTX concentration of $25 \mu \mathrm{g} / \mathrm{mL}$ was observed to be enough to completely coat the $M B s$, reaching very high absorbance values. These high values are attributed to the high surface area available for TTX immobilisation and the high amount of mAb used (1:500 dilution from stock), which was selected to not limit the detection of the immobilised TTX.

Nevertheless, when performing a competitive assay, lower mAb concentrations may provide higher sensitivities. Thus, different mAb dilutions (from 1:1000 to 1:4000) were tested to optimise the amount of $\mathrm{mAb}$. Free TTX at $10 \mathrm{ng} / \mathrm{mL}$ was added to test the sensitivity of the assay using the different mAb concentrations. mAb binding responses of 57,49 and $33 \%$ were obtained for 1:1000, 1:2000 and 1:4000 mAb dilutions, respectively, demonstrating the clear effect of the mAb concentrations on the competition assay. As a compromise between low antibody concentrations and appropriate absorbance values, 1:2000 mAb dilution was selected for subsequent experiments. The use of MBs as immobilisation supports allows performing all reaction steps in suspension, thus favouring conjugations and immunorecognition events. 


\subsection{Electrochemical MB-based immunosensing calibration curve}

317 To shift from the colorimetric approach to the electrochemical immunosensing tool, the magnetic immunocomplexes were placed on screen-printed carbon electrode arrays, thus taking benefit from performing the immunorecognition event in suspension but immobilising the immunocomplexes to provide compact and miniaturised devices for the high-throughput detection of TTXs. A schematic representation of the approach is provided in Figure 2. An electrochemical calibration curve was constructed under the conditions previously selected by colorimetry (0.5 $\mu \mathrm{L} \mathrm{MB}, 25 \mu \mathrm{g} / \mathrm{mL}$ TTX, 1:2000 mAb dilution, 1:1000 IgG-HRP dilution). The curve was background-subtracted (with respect to the controls with no mAb) and fitted to a sigmoidal logistic four-parameter equation ( $R=0.999)$ (Figure 3). A limit of detection (LOD), established as the $20 \%$ inhibition coefficient $\left(I C_{20}\right)$, of $1.2 \mathrm{ng} / \mathrm{mL}$ and a working range $\left(I C_{20}-I C_{80}\right)$ of 1.2-52.7 $\mathrm{ng} / \mathrm{mL}$ were obtained. Repeatability (intra-day precision) was appropriate according to Horwitz equation, with relative standard deviation (RSD) values of 15.4 and $6.9 \%$ at 25 and $6.3 \mathrm{ng} / \mathrm{mL}$, respectively. Reproducibility (inter-day precision) was also appropriate, with RSD values of 16.0 and $8.2 \%$ at the same TTX concentrations. The approach presented high reproducibility, certainly because of the improved assay kinetics and the low non-specific adsorption values provided by the use of MBs. Moreover, the use of MBs as immobilisation supports avoids coating the electrode surface with immunoreagents that could hinder the electron transfer. In comparison with the immunosensor for the detection of TTXs based on dithiols self-assembled directly on gold screen-printed electrodes (Reverté et al., 2017b), the MB-based immunosensor provided a broader working range (1.2-52.7 vs. $2.6-10.2 \mathrm{ng} / \mathrm{mL})$ and a lower LOD (1.2 vs. 2.6 $\mathrm{ng} / \mathrm{mL}$ ). Moreover, the use of cysteamine for TTX coating reduces the cost of the assay compared to the use of carboxylate-dithiols. In terms of the LOD and working range, results were in agreement with the electrochemical immunosensor reported by Neagu and co-workers (Neagu et al., 2006), who immobilised the antibody on the electrode and performed a competition step using TTX-alkaline phosphatase conjugate as a tracer. Merging the advantages of the easy-to- 
342 handle MBs, the high affinity of the antibody and the electrode array configuration, a useful and

343 compact tool for the detection of TTXs has been achieved.

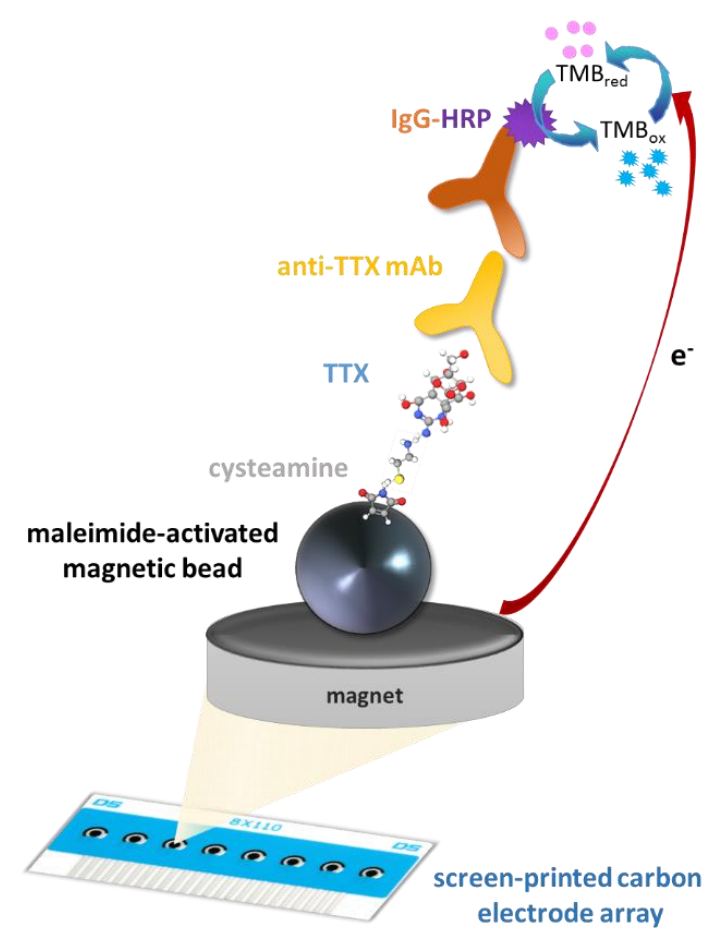

344

345 Figure 2. Schematic representation of the MB-based immunosensor for the detection of TTXs.

346

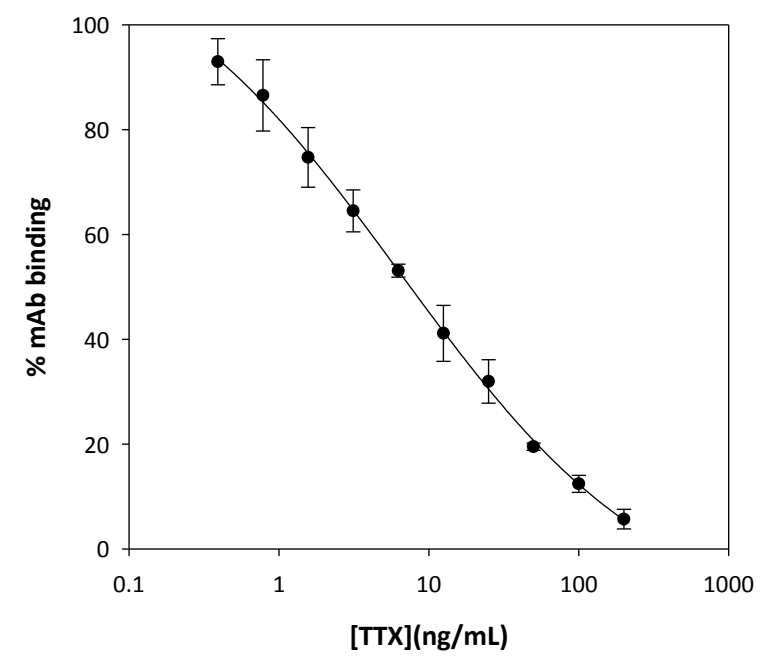

348 Figure 3. TTX calibration curve obtained by the electrochemical MB-based immunosensor. mAb binding is expressed as percentage of the control (no TTX). Error bars show SD values ( $n=3)$. 


\subsection{Detection of TTX contents in pufferfish}

351

352

353

354

355

356

357

First, skin (S) and muscle (M) tissues from both L. sceleratus juvenile specimens and internal organs containing liver and intestinal tract $(0)$ of one of the fish were analysed by the electrochemical MB-based immunosensing tool. TTX equiv. contents were detected in all samples (Table 1), and in most cases at levels above the value of $2 \mathrm{mg}$ TTX equiv./kg regarded as a criterion to judge the acceptability of pufferfish as food in Japan (HP of Ministry of Health; Noguchi \& Ebesu, 2001). Only the muscle tissue from individual 2 (M\#2) showed TTX equiv. contents below this value. These toxin levels are in the range of those found in previous studies of $L$. sceleratus adult specimens: $0.17-239.32 \mathrm{mg} / \mathrm{kg}, 0.19-87.53 \mathrm{mg} / \mathrm{kg}, 0.07-10.16 \mathrm{mg} / \mathrm{kg}$ and 0.15-6.63 mg/kg in gonads, liver, muscle and skin tissues, respectively (Acar, Ishizaki \& Nagashima, 2017; Katikou et al., 2009; Kosker et al., 2016; Rambla-Alegre et al., 2017; Reverté et al., 2015; Rodríguez et al., 2012).

LC-HRMS was then used for confirmatory purposes. The analysis revealed the presence of TTX (4-epiTTX included) in all tissues from both specimens (Figure 4, Table 1), at concentrations that ranged from 478 to $2077 \mu \mathrm{g} / \mathrm{kg}$. Additionally, some TTX analogues (11-norTTX-6(R/S)-ol, 5deoxyTTX/11-deoxyTTX, 5,11-dideoxyTTX/6,11-dideoxyTTX and 5,6,11-trideoxyTTX) were identified. Previous works have reported the presence of these and other TTX analogues (e.g. 4,9-anhydroTTX, 11-norTTX-6(R)-ol, 11-norTTX-(S)-ol) in pufferfish (Bane et al., 2014; RamblaAlegre et al., 2017; Yotsu-Yamashita, Jang, Cho \& Konoki, 2011; Yotsu-Yamashita et al., 2013). However, although the LC-HRMS chromatograms showed peaks with the exact mass for these TTX analogues (mass window $\leq \pm 1.2 \mathrm{ppm}$ ), these identifications were only tentative because their retention times could not be properly assigned (because of the lack of standards available) neither the isotopic profiles fulfilled the established criterion for identification confirmation. Consequently, only TTX/4-epiTTX quantifications are shown in Table 1. 
374 Although it is evident that the electrochemical immunosensing tool provided higher TTX

375 contents than LC-HRMS analysis, when comparing these values it is necessary to take into

376 account the detection principle of the techniques. Whereas LC-HRMS determines individual TTX

377 and TTX analogues contents that are targeted in the analysis, the immunoapproach provides a

378 global response from all TTX and TTX analogues that cross-react with the TTX antibody. This

379 cross-reactivity can differ between the different analogues and it is not necessarily related to

380 their toxicity (Reverté et al., 2015). In the hypothetical case that the TTX analogues tentatively

381 identified were really present in the samples, some of these analogues would be at

382 concentrations even higher than that of TTX. Depending on their concentration and their cross-

383 reactivity with the TTX antibody, they would contribute to a greater or lesser extent to the TTX

384 equivalent contents obtained by the immunosensing tool. LC-HRMS analysis identified only

385 sample M\#1 with levels above the value of $2 \mathrm{mg}$ TTX equiv./kg. However, LC-HRMS

386 quantifications could be underestimating the TTXs contents compared to the immunosensing

387 approaches, which identified 4 out of 5 samples with TTX equiv. contents above this level. This

different mode of recognition is not detrimental for the immunoapproach, but helps to protect consumer health. In fact, these TTX analogues would also be contributing to the toxicity of the L. sceleratus sample, in a greater or lesser extent depending on their concentration and their toxic potency (Louzao, Abal \& Vilariño, 2017). Thus, the electrochemical immunoapproach could be used as a screening tool to prevent false negative results. In case of a positive result, the sample would require complementary analyses for confirmation purposes. 
397 Table 1. TTX contents ( $\mu \mathrm{g} T \mathrm{TT} / \mathrm{kg}$ tissue) in muscle (M), skin (S) and internal organs $(\mathrm{O})$ of the 398 two L. sceleratus juveniles by the electrochemical MB-based immunosensing tool, LC-HRMS and mELISA.

\begin{tabular}{|l|c|c|c|}
\cline { 2 - 4 } \multicolumn{1}{c|}{} & \multicolumn{2}{c|}{ TTX contents ( $\mu \mathrm{g}$ TTX/kg tissue) } \\
\cline { 2 - 4 } \multicolumn{1}{c|}{} & $\begin{array}{c}\text { Electrochemical } \\
\text { immunosensing tool }\end{array}$ & LC-HRMS & mELISA \\
\hline M\#1 & 2878 & 2077 & 2327 \\
M\#2 & 1395 & 478 & 1520 \\
S\#1 & 2588 & 1239 & 2773 \\
S\#2 & 2780 & 1188 & 3175 \\
O\#2 & 2882 & 733 & 10834 \\
\hline
\end{tabular}

400

401

402

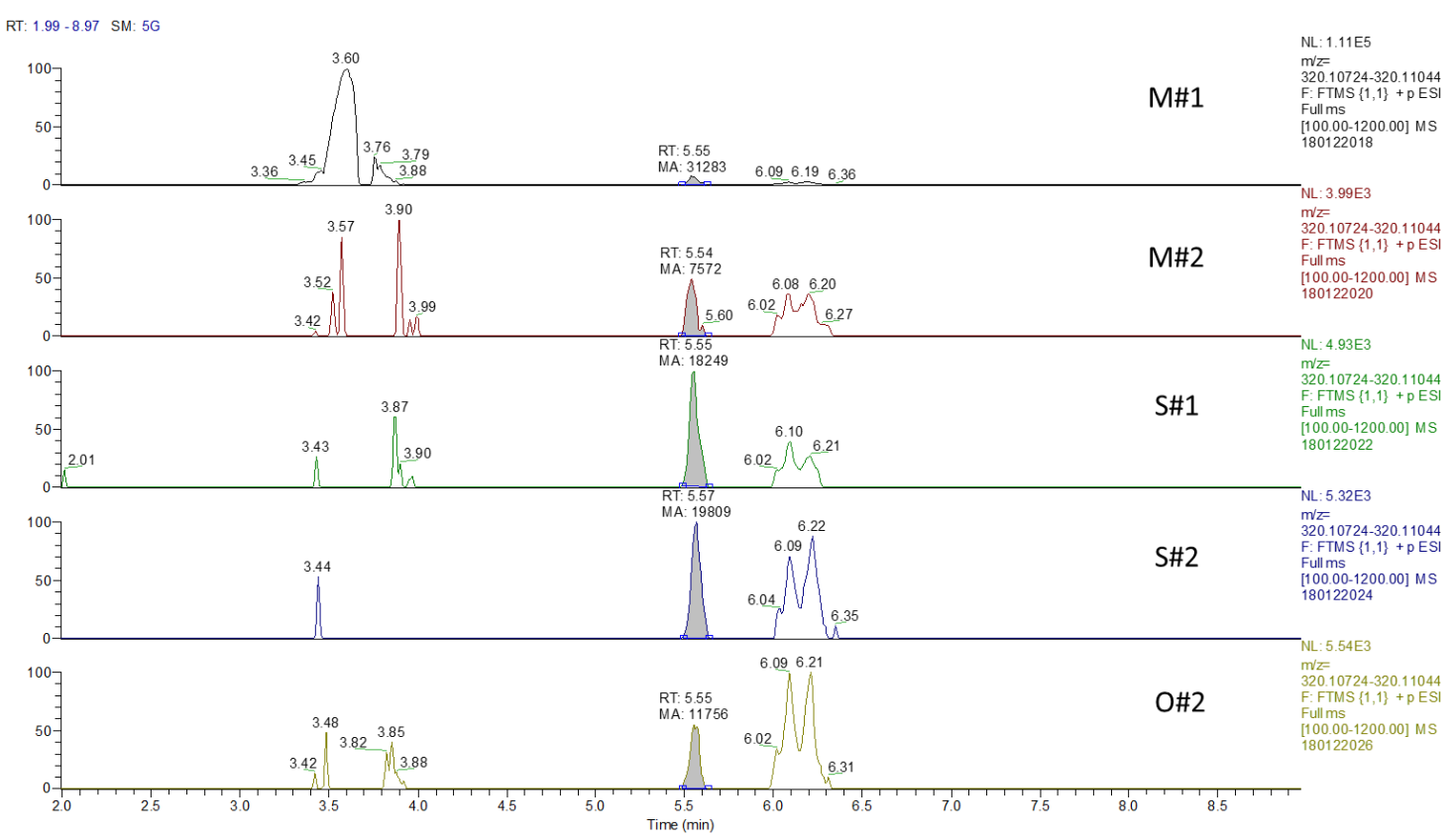

403 Figure 4. Accurate mass extracted chromatogram of TTX ([TTX+H $\left.\left.\mathrm{H}^{+}\right]\right)$(peak in grey) in L. sceleratus 404 juveniles by LC-HRMS (mass window $\pm 5 \mathrm{ppm}$ ). 
Pufferfish samples were also analysed by mELISA, which also revealed the presence of TTX equiv.

407 contents in all tissues from both pufferfish individuals (Table 1). Correlations of $81-114 \%$ were achieved between the quantifications provided by MELISA and those achieved by the electrochemical MB-based immunosensing tool in the analysis of muscle and skin tissues from both specimens, revealing no significant differences ( $\mathrm{t}=0.078, \mathrm{P}=0.940$ ). However, $\mathrm{TTX}$ equiv. contents determined by mELISA in the internal organs (O\#2) were 3.8-fold higher than those attained by the electrochemical MB-based immunosensor. In a previous work, a disparity in TTX equiv. quantifications between mELISA and LC-HRMS had been observed in the analysis of liver from a $L$. sceleratus individual caught in the Mediterranean Sea (Rambla-Alegre et al., 2017). In the current work, liver was the most abundant tissue in the internal organs sample of the specimens. Rambla-Alegre and co-workers hypothesised that other unknown TTX analogues or liver matrix compounds could be responsible for the disagreement between approaches. Nevertheless, the electrochemical MB-based immunosensing tool showed TTX equiv. contents in better accordance with LC-HRMS analysis for that sample. Both the mELISA and the electrochemical MB-based immunosensing tool being based on the same recognition principle, the TTX overestimation of mELISA seems to be more probably due to undesirable effects of some liver compounds, matrix effects that are certainly reduced by the use of MBs as immobilisation supports.

\subsection{Bacteria isolation and identification}

Several types of bacteria have been demonstrated to be the primary source of TTX, more than 30\% belonging to the genera Vibrio (Margarlamov et al., 2017). No growth on TCBS agar plates was detected, discarding the presence of Vibrio species in the juvenile pufferfish. However, most of the bacteria strains isolated in the TSA agar plates belonged to the genus Pshycrobacter (Table 
432 Alteromonas (Margalamov et al., 2017). Nonetheless, Psychrobacter has never been reported as

433 a TTX producer and thus the source of TTXs in these juvenile pufferfish remains unclear. Apart 434 from the possible presence of TTX-producing bacteria, TTX bioaccumulation through the food web could also explain the presence of TTXs in these juvenile L. sceleratus specimens from the North Aegean Sea.

\subsection{Response to the hypothesis statement}

The present study sheds further light on the toxicity status of $L$. sceleratus, detecting for the first time significant TTX contents in very small specimens of the species. These results contradict current knowledge, which considers that L. sceleratus juveniles are probably non-toxic (Sabrah et al., 2006; Katikou et al., 2009; Rodríguez et al., 2012). Biological and technical reasons could explain this discrepancy.

Toxicity variability seems to be an inherent trait in pufferfish, this variability depending on the species (Azman, Samsur \& Othman, 2014), on the maturity stage and the spawning season (Sabrah et al., 2006), and even on the specific individual (Rodríguez et al., 2012). Geographical location may also be an important factor for the toxicity of several pufferfish species (Azman et al., 2014), L. sceleratus included (Rodríguez et al., 2012). Since our specimens were immature, the size, the maturity stage and possibly the seasonality (directly linked to the spawning season) could be excluded from the list of factors that generated this discrepancy. Thus, individuality and locality probably are the main reasons, yet, for the time being, we do not have sufficient evidence regarding the contribution of each factor to this event. been applied to the analysis of TTX contents in juvenile pufferfish, thus providing different information. As previously mentioned, the MBA provides an estimation of the total toxicity, but 
it is not very specific. Immunoapproaches provide more specific and sensitive global responses

457 based on the structural recognition of TTX and its analogues by the antibody, which is not necessarily related to their toxicity. Otherwise, instrumental analysis methods allow identification of individual toxin analogues. However, if some of them are either not known or not targeted in the analysis, or if their toxicity factors have not been previously determined, analytical instrumentation may not properly estimate the potential toxicological risk of a sample. Moreover, the presence of several analogues in multi-toxin profile samples at levels below the limits of quantification of instrumental analysis methods can lead to underestimation or false negative results, in comparison with methods that provide a global response for the presence of TTX. Thus, when comparing TTX contents obtained by the different analytical methods, one should keep in mind the information provided by each one as well as their advantages and limitations. In this work, some TTX analogues others than the parent TTX were tentatively identified but could not be confirmed by LC-HRMS. Consequently, the toxicity of the sample could be underestimated if only $T \mathrm{X}$ contents are taken into account. Otherwise, if the antibody recognises TTX analogues to a different extent than their toxicity, the immunoapproach may not be properly estimating the toxicological risk of the sample. Tetraodontidae and products derived from them must not be placed on the markets (EC, 2004a; 2004b). Strong restrictions exist for import of pufferfish in the USA (FDA, 2007). In Japan, a list of edible pufferfish has been published and a value of $2 \mathrm{mg}$ TTX equiv./ $\mathrm{kg}$ has been established as a criterion to judge the acceptability of pufferfish as food, but $L$. sceleratus is labelled as a 477 non-edible species and is not included in this list (Kawabata, 1978). Thus, while some authors consider juvenile pufferfish as non-toxic when no TTX is detected, which will depend on the limit 479 of detection of the analysis technique, some other works consider L. sceleratus as non-toxic when TTX levels are below $2 \mathrm{mg} / \mathrm{kg}$. Reaching TTX contents below or above this value can depend on the recognition principle of the analysis techniques, the consideration of only parent 
482 TTX or all the different TTX analogues, and the application or not of their toxicity equivalency 483 factors (TEFs).

484 In any case, the fact that significant TTX contents were detected in such early stages of 485 L. sceleratus raises a number of important concerns regarding public health, considering that: a) 486 this species has been well established in the Mediterranean, with progressively increasing 487 abundances all over the basin, and b) L. sceleratus juveniles at these stages may intermingle with commercial species such as picarel (Spicara smaris) or anchovy (Engraulis encrasicolus). Although adult L. sceleratus are easy to identify, the situation with small specimens is quite different, as they are not so easily distinguished by non-professionals and non-experienced people. This situation calls for an enhanced vigilance by the fishermen when handling and sorting the catch, so that these fishes will not go unnoticed and reach the market.

Notwithstanding, bearing in mind the small size of these specimens, it is important to contextualise the real hazard that TTX-containing L. sceleratus juveniles pose. The minimum lethal dose of TTX for a $50 \mathrm{~kg}$ human has been reported to be $2 \mathrm{mg}$ (Noguchi \& Ebesu, 2001). Taking into consideration this value and the weight and TTX contents in the L. sceleratus juveniles examined in this study, around 500 individuals should be consumed to result in lethal effects in humans. Nevertheless, no clear information exists on the doses that can cause sublethal effects in humans. Currently, a debate in the EU exists regarding acceptable levels for TTXs in the range of 40-200 $\mu \mathrm{g} \mathrm{TTX/kg} \mathrm{in} \mathrm{shellfish} \mathrm{(EFSA,} \mathrm{2017;} \mathrm{Kasteel} \mathrm{\&} \mathrm{Westerink,} \mathrm{2017).} \mathrm{The}$ results of this study bring up the necessity for more extensive research on the toxicity of pufferfish at these early stages and the risk it may pose to consumers. The availability of fast, simple and low-cost analysis tools such as the immunosensing tool presented herein will certainly facilitate this research. 


\section{CONCLUSIONS}

508 An electrochemical immunosensing tool for the rapid screening of TTX content in juvenile 509 pufferfish has been developed. The use of MBs as TTX immobilisation supports provided 510 remarkable advantages over conventional immunoassays such as improved kinetics, reduced 511 matrix effects, higher reproducibility and versatility in the assay design. The electrochemical 512 approach provides a cost-effective, compact and miniaturised analytical tool that allows the high 513 throughput detection of TTXs. Additionally, in the optimisation of the immunosensing approach, 514 a colorimetric immunoassay has been achieved as an intermediate result, which is a valuable 515 tool for the detection of TTXs by itself.

516 The applicability of the electrochemical MB-based immunosensing tool to the determination of

517 TTX contents in pufferfish has been demonstrated, highlighting the presence of TTXs in all tissues 518 from the two juvenile L. sceleratus captured in the North Aegean Sea, which confirms our 519 hypothesis. This finding increases the risk that this species may represent for accidental consumers. Results have been compared with those provided by mELISA, showing good correlations, and confirmed by LC-HRMS. LC-HRMS analysis has suggested a multi-TTX profile of the samples and has shown the complementarity of analytical techniques based on different recognition principles. The electrochemical MB-immunosensing tool has been demonstrated to

524 be a reliable screening tool for TTXs. The availability of such user-friendly, rapid and low-cost 525 alternative analytical tools may contribute to protect human health and also to set the basis for 526 further investigation aimed to better understand the factors and the conditions under which 527 small L. sceleratus specimens become toxic. 


\section{ACKNOWLEDGEMENTS}

533 The research leading to these results has received funding from the Ministerio de Economía, 534 Industria y Competitividad through the CIGUASENSING (BIO2017-87946-C2-2-R) project. The 535 authors wish to express their gratitude to Dimitris Lachouvaris for collecting the samples and to 536 Dr Nikolaos Lambadariou for providing the map. The authors also acknowledge support from 537 CERCA Programme/Generalitat de Catalunya.

\section{REFERENCES}

Acar, C., Ishizaki, S., \& Nagashima, Y. (2017). Toxicity of the Lessepsian pufferfish Lagocephalus sceleratus from eastern Mediterranean coasts of Turkey and species identification by rapid PCR amplification. European Food Research and Technology, 243, 49-57.

Akyol, O., Ünal, V., Ceyhan, T., \& Bilecenoglu, M. (2005). First confirmed record of Lagocephalus sceleratus (Gmelin, 1789) in the Mediterranean Sea. Journal of Fish Biology, 66, 1183-1186.

Azman, A. M. N., Samsur, M., \& Othman, M. (2014). Distribution of tetrodotoxin among tissues of pufferfish from Sabah and Sarawak waters. Sains Malaysiana, 43, 1003-1011.

Bane, V., Lehane, M., Dikshit, M., O’Riordan, A., \& Furey, A. (2014). Tetrodotoxin: chemistry, toxicity, source, distribution and detection. Toxins, 6, 693-755.

Bentur, Y., Ashkar, J., Lurie, Y., Levy, Y., Azzam, Z. S., Litmanovich, M., Golik, M., Gurevych, B., Golani, D., \& Eisenman, A. (2008). Lessepsian migration and tetrodotoxin poisoning due to Lagocephalus sceleratus in the eastern Mediterranean. Toxicon, 52, 964-968. 

tetrodotoxin (TTX) and TTX analogues in marine bivalves and gastropods, EFSA Journal, 15(4), 4752.

EC (European Commission), 2004a. Regulation (EC) No 854/2004 of the European Parliament and of the council of 29 april 2004 laying down specific rules for the organisation of official controls on products of animal origin intended for human consumption. Official Journal of the European Union, L226, 83-127. and of the council of 29 April 2004 laying down specific hygiene rules for food of animal origin. Official Journal of the European Union, L139, 22-82.

FDA (Food and Drug Administration) (2017). Advisory on Puffer Fish. (2007). https://www.fda.gov/Food/ResourcesForYou/Industry/ucm085458.htm Accessed 10 October 2018.

Galil, B., Boero, F., Fraschetti, S., Piraino, S., Campell, M., Hewitt, C., Carlton, J., Cook, E., Jelmert,

A., Macpherson, E., Marchini, A., Occhipinti-Ambrogi, A., Mckenzie, C., Minchin, D., Ojaveer, H., Olenin, S., \& Ruiz, G. (2015). The enlargement of the Suez Canal and introduction of nonindigenous species to the Mediterranean Sea. Limnology and Oceanography Bulletin, 24(2), 4345.

572 Golani, D., \& Levy, Y. (2005). New records of rare occurrences of fish species from the 573 Mediterranean coast of Israel. Zoology in the Middle East, 36, 27-32.

574 HP of Ministry of Health, Labour and Welfare of Japan. 575 http://www.mhlw.go.jp/topics/syokuchu/poison/animal_01.html Accessed on 8 August 2018.

576 Kalogirou, S. (2013). Ecological characteristics of the invasive pufferfish Lagocephalus sceleratus 577 (Gmelin, 1789) in Rhodes, Eastern Mediterranean Sea. A case study. Mediterranean Marine 
Kara, M. H., Ben Lamine, E., \& Francour, P. (2015). Range expansion of an invasive pufferfish,

580 Lagocephalus sceleratus (Actinopterygii: Tetraodontiformes: Tetraodontidae), to the southwestern Mediterranean. Acta Ichthyologica et Piscatoria, 45, 103-108.

Kasapidis, P., Peristeraki, P., Tserpes, G., \& Magoulas, A. (2007). First record of the Lessepsian migrant Lagocephalus sceleratus (Gmelin 1789) (Osteichthyes: Tetraodontidae) in the Cretan Sea (Aegean, Greece). Aquatic Invasions, 1, 71-73.

Kasteel, E. E., \& Westerink, R. H. (2017) Comparison of the acute inhibitory effects of Tetrodotoxin (TTX) in rat and human neuronal networks for risk assessment purposes. Toxicology Letters, 270, 12-16.

Katikou, P., Georgantelis, D., Sinouris, N., Petsi, A., \& Fotaras, T. (2009). First report on toxicity assessment of the Lessepsian migrant pufferfish Lagocephalus sceleratus (Gmelin, 1789) from European waters (Aegean Sea, Greece). Toxicon, 54, 50-55. Issaris, Y., Izquierdo-Gomez, D., Izquierdo-Munoz, A., Kavadas, S., Koehler, L., Konstantinidis, E., Mazza, G., Nowell, G., Önal, U., Özen, M. R., Pafilis, P., Pastore, M., Perdikaris, C., Poursanidis, D., Prato, E., Russo, F., Sicuro, B., Tarkan, A. N., Thessalou-Legaki, M., Tiralongo, M., Mediterranean Biodiversity Records (October, 2014). Mediterranean Marine Science, 15, 675695.

Kawabata, T. (1978). Assay method for tetrodotoxin. In Ministry of Health and Welfare. (Eds.), Food hygiene examination manual (pp. 232-240). Tokyo. Japan Food Hygiene Association. enzyme immunoassay for quantitative determination of tetrodotoxin. Japanese journal of medical science \& biology, 50, 133-150. 
604

605

606

607

608

609

610

611

612

613

614

615

616

617

618

619

620

621

622

623

624

625

626

627

Kheifets, J., Rozhavsky, B., Solomonovich, Z. G., Marianna, R., \& Soroksky, A. (2012). Severe Tetrodotoxin poisoning after consumption of Lagocephalus sceleratus (Pufferfish, Fugu) fished in Mediterranean Sea, treated with cholinesterase inhibitor. Case Reports in Critical Care, 782507.

Kiriake, A., Ohta, A., Okayama, S., Matsuura, K., Ishizaki, S., \& Nagashima, Y. (2016). Molecular identification and toxicity of pufferfish juveniles contaminating whitebait products. Journal of the Food Hygienic of Japan, 57, 13-18.

Kochzius, M., Seidel, C., Antoniou, A., Botla, S. K., Campo, D., Cariani, A., Vazquez, E. G, Hauschild, J., Hervet, C., Hjorleifsdottir, S., Hreggvidsson, G., Kappel, K., Landi, M., Magoulas, A., Marteinsson, V., Nolte, M., Planes, S., Tinti, F., Turan, C., Venugopal, M. N., Weber, H., \& Blohm, D. (2010). Identifying Fishes through DNA Barcodes and Microarrays. PlosOne, 5, e12620.

Kosker, A.R., Özogul, F., Durmus, M., Ucar, Y., Ayas, D., Regenstein, J.M., \& Özogul, Y. (2016). Tetrodotoxin levels in pufferfish (Lagocephalus sceleratus) caught in the northeastern Mediterranean sea. Food Chemistry 210, 332-337.

Kreuzer, M.P., Pravda, M., O'Sullivan, C.K., \& Guilbault, G.G. (2002). Novel electrochemical immunosensors for seafood toxin analysis. Toxicon, 40, 1267-1274.

Leonardo, S., Reverté, L., Diogène, J., \& Campàs, M. (2016). Biosensors for the Detection of Emerging Marine Toxins. In D. P. Nikolelis, \& G. P. Nikoleli (Eds.), Biosensors for Security and Bioterrorism Applications, Advanced Sciences and Technologies for Security Applications (pp. 231-248). Switzerland, Springer.

Leonardo, S., Toldrà, A., \& Campàs, M. (2017). Trends and Prospects on Electrochemical Biosensors for the Detection of Marine Toxins, In J. Diogène, \& M. Campàs (Eds.), Recent Advances in the Analysis of Marine Toxins. Comprehensive Analytical Chemistry (pp. 303-341). Elsevier. 
Louzao, M.C., Abal, P., \& Vilariño, N. (2017). Toxicity equivalence factors for regulated and nonregulated marine toxins. Current Opinion in Food Science, 18, 64-70.

Margarlamov, T. Y., Melnikova, D. I., \& Chernyshev, A. V. (2017). Tetrodotoxin-producing bacteria: Detection, distribution and migration of the toxin in aquatic systems. Toxins 9, 166.

Nader, M., Indary, S., \& Boustany, L. (2012). FAO EastMed The Puffer Fish Lagocephalus sceleratus (Gmelin, 1789) in the Eastern Mediterranean. GCP/INT/041/EC - GRE - ITA/TD-10.

Neagu, D., Micheli, L., \& Palleschi, G. (2006). Study of a toxin-alkaline phosphatase conjugate for the development of an immunosensor for tetrodotoxin determination. Analytical and bioanalytical chemistry, 385, 1068-1074.

Noguchi, T., \& Ebesu, J. S. M. (2001). Puffer poisoning: Epidemiology and treatment. Journal of Toxicology-Toxin Reviews, 20, 1-10.

Peristeraki, P., Lazarakis, G., Skarvelis, C., Georgiadis, M., \& Tsepres, G. (2006). Additional records on the occurrence of alien fish species in the eastern Mediterranean Sea. Mediterranean Marine Science, 7(2), 61-66.

Pinacho, D.G., Sánchez-Baeza, F., Pividori, M.I., \& Marco, M.-P. (2014). Electrochemical detection of fluoroquinolone antibiotics in milk using a magneto immunosensor. Sensors, 14, $15965-15980$.

Pividori, M.I., \& Alegret, S. (2010). Micro and nanoparticles in biosensing systems for food safety and environmental monitoring. An example of converging technologies. Microchim Acta, 170, 227-242.

Rambla-Alegre, M., Reverté, L., del Río, V., de la Iglesia, P., Palacios, O., Flores, C., Caixach, J., Campbell, K., Elliott, C. T., Izquierdo-Muñoz, A., Campàs, M., \& Diogène, J. (2017). Evaluation of tetrodotoxins in caught along the Mediterranean coast of Spain. Toxin profile of Lagocephalus sceleratus. Environmental Research, 158, 1-6. 
652 Rambla-Alegre, M., Leonardo, S., Barguil, Y., Flores, C., Caixach, J., Campbell, K., Elliott, C.T., 653 Maillaud, C., Boundy, M.J., Harwood, D.T., Campàs, M., \&, Diògene, J. (2018). Rapid screening 654 and multi-toxin profile confirmation of tetrodotoxins and analogues in human body fluids derived from a puffer fish poisoning incident in New Caledonia. Food and Chemical Toxicology, $112,188-193$.

657

Reverté, L., Soliño, S., Carnicer, O., Diogène, J., \& Campàs, M. (2014). Alternative Methods for 658 the Detection of Emerging Marine Toxins: Biosensors, Biochemical Assays and Cell-Based Assays. Marine Drugs, 12, 5719-5763.

Reverté, L., de la Iglesia, P., del Río, V., Campbell, K., Elliott, C. T., Kawatsu, K., Katikou, P., monolayer-based immunoassay and comparison with surface plasmon resonance, LC-MS/MS and mouse bioassay. Analytical Chemistry, 87, 10839-10847. C.T., \& Campbell, K. (2017a). Tetrodotoxin detection in puffer fish by a sensitive planar waveguide immunosensor. Sensors and Actuators B-Chemical, 253, 967-976.

Reverté, L., Campbell, K., Rambla-Alegre, M., Elliott, C.T., Diogène, J., \& Campàs, M. (2017b). Immunosensor array platforms based on self-assembled dithiols for the electrochemical detection of tetrodotoxins in puffer fish. Analytical Chimica Acta, 9, 95-10.

Reverté, L., Rambla-Alegre, M., Leonardo, S., Bellés, C., Campbell, K., Elliott, C. T., Gerssen, A., Klijnstra, M. D., Diogène, J., \& Campàs, M. (2018). Development and validation of a maleimidebased enzyme-linked immunosorbent assay for the detection of tetrodotoxins in oysters and mussels. Talanta, 176, 659-666. chromatography-mass spectrometry method to detect Tetrodotoxin and its analogues in the 
676

677

678

679

680

681

682

683

684

685

686

687

688

689

690

691

692

693

puffer fish Lagocephalus sceleratus (Gmelin, 1789) from European waters. Food Chemistry, 132, $1103-1111$.

Sabrah, M. M., El-Ganainy, A. A., \& Zaky, M. A. (2006). Biology and toxicity of the pufferfish Lagocephalus sceleratus (Gmelin, 1789) from the Gulf of Suez. Egyptian Journal of Aquatic Research, 32, 283-297.

Smith, M., \& Heemstra, P. (1986). Tetraodontidae. In M. M. Smith, \& P. C. Heemstra (Eds.), Smith's Sea Fishes (pp. 894-903). Berlin: Springer-Verlag.

Tang, Y., Huang, S., Xu, J., Ouyang, G., \& Liu, Y. (2018). PLGA-based nanofibers with a biomimetic polynoradrenaline sheath for rapid in vivo sampling of tetrodotoxin and sulfonamides in pufferfish. Journal of Materials Chemistry B, 22, 3603-3822.

Yotsu-Yamashita, M., Jang, J.H., Cho, Y., \& Konoki, K. (2011). Optimization of simultaneous

analysis of tetrodotoxin, 4-epitetrodotoxin, 4,9-anhydrotetrodotoxin, and 5,6,11trideoxytetrodotoxin by hydrophilic interaction liquid chromatography-tandem mass spectrometry. Forensic Toxicology, 29, 61-64.

Yotsu-Yamashita, M., Abe, Y., Kudo, Y., Ritson-Williams, R., Paul, V.J., Konoki, K., Cho, Y., Adachi, M., Imazu, T., Nishikawa, T., \& Isobe, M. (2013). First identification of 5,11-dideoxytetrodotoxin in marine animals, and characterisation of major fragment ions of tetrodotoxin and its analogs by high resolution ESI-MS/MS. Marine Drugs, 11, 2799-2813. 